Kwan Y. Chong MB BS, *

Rosemary A. Craen MB BS, *

John M. Murkin MD, *

Donald Lee MD, $\dagger$

Michael Eliasziw PhD, $\ddagger$

Adrian. W. Gelb MB CHB*

\section{Rate of change of cere- bral blood flow velocity with hyperventilation during anesthesia in humans}

Purpose: Although it has been suggested that the rate at which the cerebral circulation responds to changes in $\mathrm{PaCO}_{2}$ is different with differing anesthetics, there have been no attempts to measure this. Transcranial Doppler allows the continuous measurement of cerebral blood flow velocity (CBFV) and any changes over time. Our aim was to compare the rate of change of $\mathrm{CBFV}$ when end-tidal $\mathrm{CO}_{2}\left(\mathrm{P}_{\mathrm{ET}} \mathrm{CO}_{2}\right)$ was rapidly altered during halothane or isoflurane anesthesia.

Methods: Twenty-eight unpremedicated healthy patients were randomly assigned to receive air $/ \mathrm{O}_{2}$ and either I - I.5 MAC halothane or isoflurane as the primary anesthetic. After 15 min of steady state, $\mathrm{P}_{\mathrm{ET}} \mathrm{CO}_{2}$ was rapidly reduced from $45 \mathrm{mmHg}$ to $30 \mathrm{mmHg}$. CBFV and $\mathrm{P}_{E T} \mathrm{CO}_{2}$ were recorded every $30 \mathrm{sec}$ for the next $10 \mathrm{~min}$.

Results: The rate of change of normalized CBFV ( $\Delta$ CBFV vs $\Delta$ time) was more rapid in the isoflurane group ( $P$ $<0.000 \mathrm{I}$ ) especially in the initial few minutes. In all patients anesthetized with isoflurane, and in all but two patients anesthetized with halothane, the reduction in $\mathrm{P}_{E T} \mathrm{CO}_{2}$ produced a corresponding decrease in CBFV. However, there were no differences in the magnitude of cerebrovascular $\mathrm{CO}_{2}$ reactivity $\left(\Delta \mathrm{CBFV}\right.$ vs $\left.\Delta \mathrm{P}_{\mathrm{ET}} \mathrm{CO}_{2}\right)$ between the two groups.

Conclusions: The rate of change of CBFV was faster in the isoflurane than in the halothane group especially in the initial few minutes. Indeed, for two patients in the halothane group Vmca did not change despite a change in $\mathrm{P}_{\mathrm{ET}} \mathrm{CO}_{2}$. This may be of clinical importance when cerebrovascular tone needs to be changed rapidly.

Objectif : Bien qu'on ait suggéré que la vitesse à laquelle la circulation cérébrale répondant aux changements de $\mathrm{PaCO}_{2}$, varie selon le type d'anesthésique, aucun essai ne l'a mesurée. Le Doppler transcrânien permet la mesure continue de la vitesse du flux sanguin cérébral (VFSC) pour chaque changement dans le temps. Notre but était de comparer la vitesse de changement de la VFSC quand le $\mathrm{CO}_{2}$ de fin d'expiration $\left(\mathrm{la}_{\mathrm{ET}} \mathrm{CO}_{2}\right)$ était modifié rapidement pendant l'anesthésie à l'halothane ou à l'isoflurane.

Méthode : Vingt-huit patients en santé, sans prémédication, ont été répartis au hasard et ont reçu un mélange air $/ \mathrm{O}_{2}$ et I - I,5 CAM d'halothane ou d'isoflurane comme principal anesthésique. Après I 5 min de stabilité, la $\mathrm{P}_{\mathrm{ET}} \mathrm{CO}_{2}$ a été réduite rapidement de $45 \mathrm{mmHg}$ à $30 \mathrm{mmHg}$. La VFSC et la $\mathrm{P}_{E T} \mathrm{CO}_{2}$ ont été enregistrées toutes les 30 s pendant les 10 min suivantes.

Résultats : La vitesse de changement de la VFSC normalisée ( $\Delta$ VFSC vs $\Delta$ temps) a été plus rapide avec l'isoflurane $(P<0,000 \mathrm{I})$ surtout pendant les premières minutes. Chez tous les patients anesthésiés avec l'isoflurane, et chez tous sauf deux patients anesthésiés avec l'halothane, la réduction de la $\mathrm{P}_{\mathrm{ET}} \mathrm{CO}_{2}$ a entraîné une baisse correspondante de la VFSC. Toutefois, il n'y a pas eu de différence intergroupe quant à la réactivité du $\mathrm{CO}_{2}$ cérébrovasculaire ( $\Delta$ VFSC vs $\Delta \mathrm{P}_{\mathrm{ET}} \mathrm{CO}_{2}$ ).

Conclusion : Le changement de la VFSC a été plus rapide avec l'isoflurane qu'avec l'halothane, surtout pendant les premières minutes. II est à noter que pour deux patients qui ont reçu l'halothane, la VFSC n'a pas changé malgré une modification de la $\mathrm{P}_{\mathrm{ET}} \mathrm{CO}_{2}$. Cette constatation a des répercussions cliniques, quand le tonus cérébrovasculaire doit être rapidement modifié.

From the Departments of Anaesthesia* and Diagnostic Radiology, $\nmid$ London Health Sciences Centre, University Campus and Department of Epidemiology and Biostatistics, $\ddagger$ The University of Western Ontario, London, Ontario, Canada.

Address correspondence to: Dr. A.W. Gelb, Department of Anaesthesia, London Health Sciences Centre, University Campus, 339

Windermere Rd, London, Ontario, N6A 5A5 Canada. Phone: 519-663-3828; Fax: 519-663-3161; E-mail: agelb@julian.uwo.ca

Presented at the American Society of Anesthesiologists Annual Meeting and at the Society of Neurosurgical Anesthesia and Critical care Annual Meeting, October 1992.

Accepted for publication October 8, 1999

CAN J ANESTH 2000/47: / pp 125-130 
I T has previously been reported that if $\mathrm{PaCO}_{2}$ is reduced concomitantly with the introduction of isoflurane, intracranial pressure (ICP) does not increase. ${ }^{l}$ Conversely, simultaneous induction of hypocapnia with the introduction of halothane does not prevent increases in ICP. ${ }^{2}$ However, if 10 min of hyperventilation to $\mathrm{PaCO}_{2}$ levels of $<30$ $\mathrm{mmHg}$ is carried out before introducing halothane, increases in ICP can be minimized or abolished. ${ }^{2}$ Although these two studies give the impression that the rate at which the cerebral circulation responds to changes in $\mathrm{PaCO}_{2}$ is different with these two anesthetics, there have been no subsequent attempts to measure the rate of cerebrovascular responsiveness to changes in $\mathrm{CO}_{2}$ during anesthesia.

Transcranial Doppler (TCD) provides an opportunity to measure cerebral blood flow velocity (CBFV) continuously and noninvasively and, thereby, to record instantaneous changes in CBFV. The aim of our study was to compare the rate of change of CBFV when end-tidal $\mathrm{CO}_{2}\left(\mathrm{P}_{\mathrm{ET}} \mathrm{CO}_{2}\right)$ was rapidly altered during halothane or isoflurane anesthesia.

Methods

With institutional review board approval and after obtaining informed consent, 28 patients, ASA physical status 1 or 2 , undergoing non-neurosurgical and noncardiac surgical procedures were recruited. The subjects were chosen on the basis that they did not have overt cerebrovascular disease and that their surgery did not involve manipulations of the head and neck nor would it be associated with large fluctuations in blood pressure. Patients were then randomly assigned to receive either halothane or isoflurane as the primary anesthetic.

\section{Anesthetic management}

No premedication was given to either group. In both groups anesthesia was induced using 4-5 $\mathrm{mg} \cdot \mathrm{kg}^{-1}$ thiopental, $1-2 \mu \mathrm{g} \cdot \mathrm{kg}^{-1}$ fentanyl and 1-2 $\mathrm{mg} \cdot \mathrm{kg}^{-1}$ succinylcholine. After tracheal intubation, the lungs were ventilated with air $/ \mathrm{O}_{2}\left(\mathrm{~F}_{\mathrm{I}} \mathrm{O}_{2} 0.4\right)$ and either 1 - 1.5 MAC halothane or isoflurane according to surgical need. Muscle relaxation was maintained with atracurium. A modified Mapleson D (coaxial) breathing circuit was used so that $\mathrm{P}_{\mathrm{ET}} \mathrm{CO}_{2}$ could be rapidly changed by altering fresh gas flow rates without altering respiratory rate, tidal volume or adding exogenous $\mathrm{CO}_{2}$.

\section{Monitoring}

In all subjects the following monitors were used: noninvasive blood pressure (Spacelab 90603A), electrocardiogram, nasopharyngeal temperature probe and pulse oximetry. End-tidal concentrations of $\mathrm{CO}_{2}$, isoflurane and halothane were measured at the proximal end of the tracheal tube and analyzed by Nellcor - 2500 anaesthetic gas monitor.

\section{Determination of mean middle cerebral artery flow velocity}

A pulsed range-gated type of transcranial Doppler (Transpect, Medasonics Fremont $\mathrm{Ca}$ ) was used. The transducer was applied in the region of the temporal window above the zygomatic arch. Low frequency ultrasound in the range of $1.5-2.5 \mathrm{MHz}$ was used to penetrate the thin temporal bone to locate the middle cerebral artery at a depth of approximately $45-50$ $\mathrm{mm}$. The optimal signal from the vessel was obtained using an indicator on the machine showing when this was present, as well as good waveforms, and a good volume of sound returning from the patient (both reflections of a good acoustic window). The transducer was then immobilized in that specific position and at that specific angle to the patient's head, using a head strap. The peak systolic and diastolic CBFV were recorded on thermal paper for subsequent analysis by one of the investigators (DL) who was blinded to the treatment group. Mean middle cerebral artery blood flow velocity (Vmca) values were measured directly from the wave forms, averaged over two to three cardiac cycles, and calculated using the formula: Vmca $=1 / 3$ (peak systolic flow velocity - end diastolic flow velocity) + end diastolic flow velocity.

\section{Study protocol}

In each patient, an end-tidal concentration of halothane or isoflurane equivalent to $\mathrm{I} \mathrm{MAC}$ was aimed for and then titrated according to surgical need. After $15 \mathrm{~min}$ at a steady end-tidal concentration of $1-1.5 \mathrm{MAC}$ and $\mathrm{P}_{\mathrm{ET}} \mathrm{CO}_{2}$ of $45 \mathrm{mmHg}$, a baseline set of data was recorded (blood pressure, heart rate, nasopharyngeal temperature, $\mathrm{P}_{\mathrm{ET}} \mathrm{CO}_{2}$ and Vmca). The fresh gas flow rate was then adjusted so that a $\mathrm{P}_{\mathrm{ET}} \mathrm{CO}_{2}$ of $30 \mathrm{mmHg}$ was rapidly achieved without altering the $\mathrm{F}_{\mathrm{I}} \mathrm{O}_{2}$ or end-tidal concentration of the inhalational agents. Vmca and $\mathrm{P}_{\mathrm{ET}} \mathrm{CO}_{2}$ were recorded every $30 \mathrm{sec}$ and blood pressure and heart rate were recorded every one minute for $10 \mathrm{~min}$.

\section{Data analysis}

Individual patient Vmca - $\mathrm{CO}_{2}$ responses: As the conventional method of displaying $\mathrm{CBF}-\mathrm{CO}_{2}$ responses utilizes linear regression analysis, we have followed this practice as well. For each patient, we have calculated the slope using all data points (measured Vmca at corresponding $\mathrm{P}_{\mathrm{ET}} \mathrm{CO}_{2}$ ) and then compared the two groups using an unpaired t test. 
Vmca - time responses: Due to the wide inter-individual variation in Vmca, we used normalized Vmca values for Vmca-time analyses. Normalized Vmca values are the measured Vmca values expressed as a percentage of baseline Vmca at $\mathrm{P}_{\mathrm{ET}} \mathrm{CO}_{2} 45 \mathrm{mmHg}$ for that patient. We then used nonlinear regression analysis for modelling normalized Vmca over time. An indicator variable was added to the regression equation to represent group membership, which then allowed a test of whether the relationship between normalized Vmca and time was the same or different in the two drug groups. For patients in the isoflurane group, the indicator variable was assigned the value 0 and for patients in the halothane group, the value 1 . We also examined the rate of decrease in $\mathrm{P}_{\mathrm{ET}} \mathrm{CO}_{2}$ over 10 min in both groups and compared the time taken for $\mathrm{P}_{\mathrm{ET}} \mathrm{CO}_{2}$ to be reduced to a stable value.

We used Chi-square tests for comparing categorical data and repeated measures ANOVA and Student $t$ test for comparing physiological data. Results with $P$ values $<0.05$ were regarded as statistically significant. All values are reported in terms of mean \pm standard deviation.

Results

Anesthesia and surgery were uneventful for all patients and there were no complications arising from the use of TCD. However, one patient from the halothane group was dropped from the analyses because $\mathrm{P}_{\mathrm{ET}} \mathrm{CO}_{2}$ increased towards the end of the study period due to release of a leg tourniquet. Henceforth, our analyses pertain to 13 patients in the halothane group and 14 patients in the isoflurane group. There were no differences between groups in demographic data, blood pressure, heart rate, hemoglobin or temperature (Table).

There was no difference between groups in the rate of decrease in $\mathrm{P}_{\mathrm{ET}} \mathrm{CO}_{2}$ over $10 \mathrm{~min}$. In addition, there was no difference in the time required for $\mathrm{P}_{\mathrm{ET}} \mathrm{CO}_{2}$ to

TAB LE Comparison of demographics and physiological parameters in halothane and isoflurane groups*

\begin{tabular}{lll}
\hline & Halothane & Isoflurane \\
\hline Number of patients & 13 & 14 \\
Age $(\mathrm{yr})$ & $38 \pm 13$ & $35 \pm 12$ \\
Sex $(\mathrm{M}: \mathrm{F})$ & $7: 6$ & $11: 3$ \\
Weight $(\mathrm{kg})$ & $79 \pm 20$ & $77 \pm 16$ \\
Hemoglobin $\left(\mathrm{g} \cdot \mathrm{dl}^{-1}\right)$ & $14.3 \pm 1.1$ & $14.6 \pm 0.8$ \\
Heart rate $\left(\right.$ beats. $\mathrm{min}^{-1)}$ & $70 \pm 9$ & $72 \pm 16$ \\
MABP $(\mathrm{mmHg})$ & $81 \pm 8$ & $83 \pm 8$ \\
Temperature $\left({ }^{\circ} \mathrm{C}\right)$ & $36.7 \pm 0.4$ & $36.3 \pm 0.3$ \\
\hline
\end{tabular}

* Inter-group comparisons were statistically non-significant

Values are mean \pm SD. MABP $=$ mean arterial blood pressure.
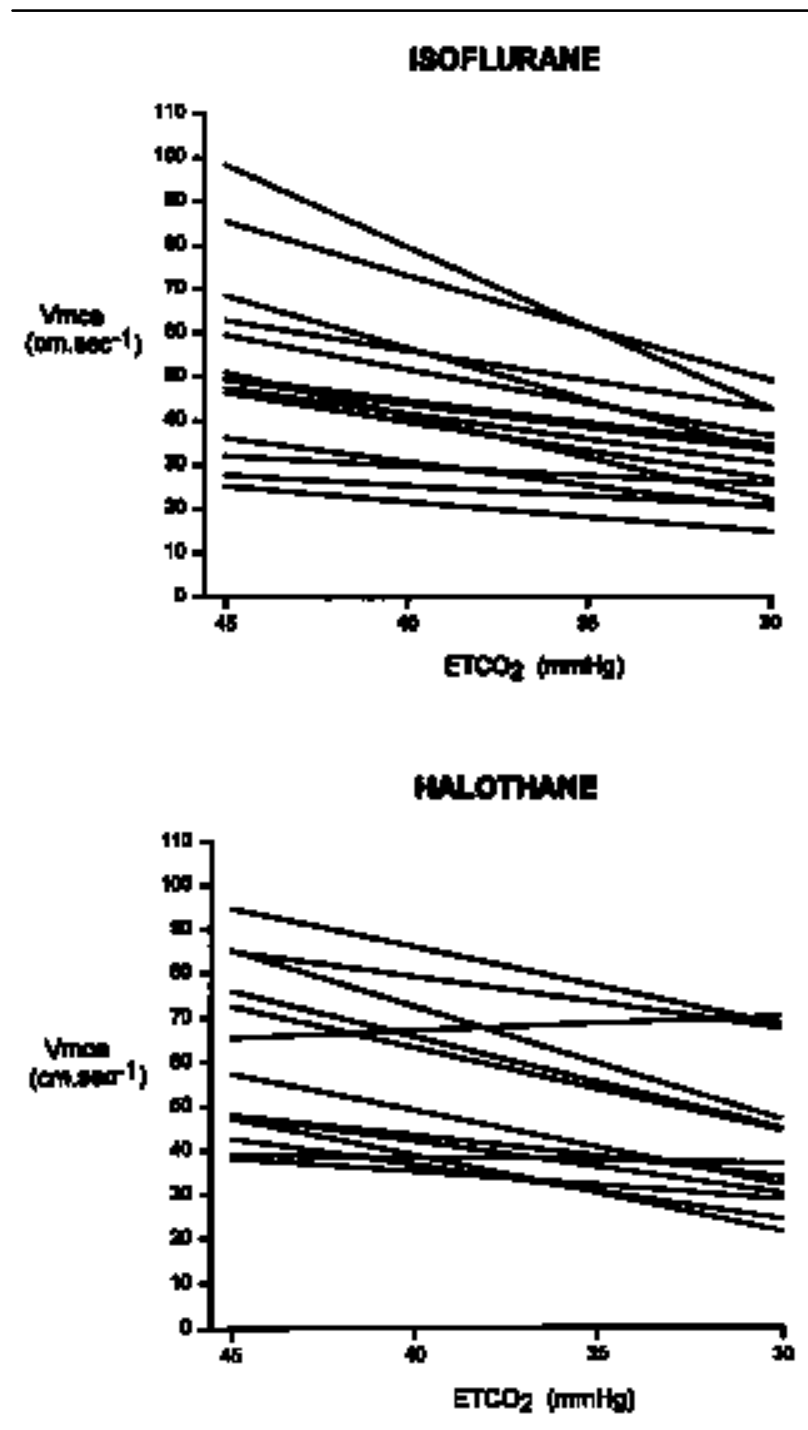

FIGURE 1 For each individual in the isoflurane $(n=14)$ and halothane $(n=13)$ groups, the lines of best fit were obtained using all data points representing measured Vmca (mean middle cerebral blood flow velocity) as end-tidal $\mathrm{CO}_{2}\left(\mathrm{P}_{\mathrm{ET}} \mathrm{CO}_{2}\right)$ was reduced from $45 \mathrm{mmHg}$ to $30 \mathrm{mmHg}$. There was no difference between groups in responses. The slope of Vmca $-\mathrm{P}_{\mathrm{ET}} \mathrm{CO}_{2}\left(\mathrm{~cm} \cdot \mathrm{sec}^{-1} \cdot \mathrm{mmHg}^{-1}\right)$ for isoflurane was $1.5 \pm 0.9$ and for halothane $1.3 \pm 0.8, P=0.6$.

Values are mean \pm SD.

be reduced to a stable value, $3 \pm 0.7$ and $2.9 \pm 0.9 \mathrm{~min}$ for isoflurane and halothane respectively.

In all patients anesthetized with isoflurane (endtidal concentration $=1.2 \pm 0.2 \mathrm{vol} \%)$, and in all but two patients anesthetized with halothane (end-tidal concentration $=0.98 \pm 0.1 \mathrm{vol} \%)$, the reduction in $\mathrm{P}_{\mathrm{ET}} \mathrm{CO}_{2}$ produced a corresponding decrease in Vmca (Figure 1). From regression analyses, Vmca $-\mathrm{P}_{\mathrm{ET}} \mathrm{CO}_{2}$ 
responses $\left(\mathrm{CO}_{2}\right.$ reactivity) for both groups were not different, $1.5 \pm 0.9$ and $1.3 \pm 0.8 \mathrm{~cm} \cdot \mathrm{s}^{-1} \cdot \mathrm{mmHg}^{-1}$ for isoflurane and halothane respectively $(P=0.6)$.

The relationship between normalized Vmca and time in both groups was best described by a third order polynomial (cubic) equation. ${ }^{3}$ The regression equation is written as:

Normalized Vmca $=102.1-(18.1 \times$ Time $)+(2.6 \times$ Time $\left.^{2}\right)-\left(0.1 \times\right.$ Time $\left.^{3}\right)+(1.3 \times$ Group $x$ Time $)$, where Group is the indicator variable. A test of the regression coefficient corresponding to the Group $\times$ Time term (i.e., 1.3) was different from zero $(P<0.0001)$, indicating a difference between drug groups. By substituting the values 0 and 1 in place of Group, two separate regression equations were obtained corresponding to the isoflurane and halothane groups, respectively. Specifically, the curve plotted in Figure 2 for the isoflurane group corresponds to the equation:

Normalized Vmca $=102.1-(18.1 \times$ Time $)+(2.6$ $\times$ Time $\left.^{2}\right)-\left(0.1 \times\right.$ Time $\left.^{3}\right)$

For the curve corresponding to the halothane group, the regression equation is:

Normalized Vmca $=102.1-(16.8 \times$ Time $)+(2.6$ $\times$ Time $\left.^{2}\right)-\left(0.1 \times\right.$ Time $\left.^{3}\right)$

From the separate regression equations and from Figure 2 it is observed that the rate of change of Vmca was more rapid in the isoflurane group (-18.1 units per minute) compared with the halothane group (-16.8 units per minute), especially in the initial few minutes. As the time at which normalized Vmca started to decrease (onset time) and the rate of decrease in $\mathrm{P}_{\mathrm{ET}} \mathrm{CO}_{2}$ over 10 min were the same for both groups,

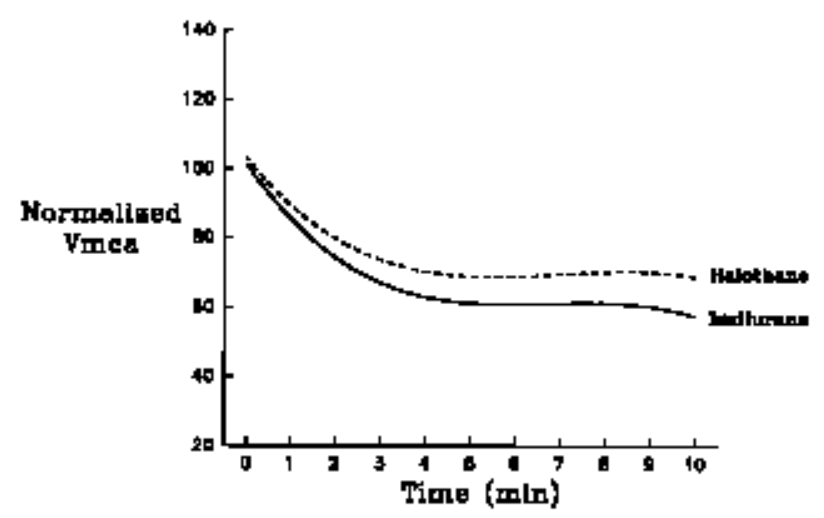

FIGURE 2 Lines representing the rates of change of normalized Vmca over $10 \mathrm{~min}$ for isoflurane $(\mathrm{n}=14)$ and halothane $(\mathrm{n}=13)$. The relationship between the rate of change of normalized Vmca with respect to time is best described by a third order polynomial equation. ${ }^{3}$ There was a difference between the two curves, $P<$ 0.0001 . See text for details. these factors did not contribute to the differences observed between the curves.

Discussion

When investigating the effects of anesthetics on cerebrovascular reactivity to $\mathrm{CO}_{2}$, it has been traditional to measure the change in $\mathrm{CBF}$ or in $\mathrm{CBFV}$ at two static carbon dioxide levels. However, transcranial Doppler offers the opportunity of studying the cerebral circulation during dynamic conditions. We have therefore used TCD to examine the rate of change of CBFV when $\mathrm{CO}_{2}$ levels were rapidly altered during isoflurane or halothane anesthesia. This technique also allowed us to examine not only the rate of change but also the response time of the cerebrovasculature to changing $\mathrm{CO}_{2}$ in the presence of these agents.

Our study shows a difference between the two groups in the rate of change of normalized Vmca, the slope being steeper in the isoflurane group than in the halothane group (Figure 2). This disparity was not due to a difference either in the rate of decrease in $\mathrm{P}_{\mathrm{ET}} \mathrm{CO}_{2}$ over 10 min or in the onset time at which Vmca started to decrease once $\mathrm{P}_{\mathrm{ET}} \mathrm{CO}_{2}$ had been changed. These results indicate that the rate at which the cerebral circulation responds to changes in $\mathrm{CO}_{2}$ is faster with isoflurane than with halothane. The mechanisms underlying these differences between inhalational agents were not investigated in this study and can only be speculated upon. It seems highly unlikely that halothane and isoflurane would have differential effects on the movement of $\mathrm{CO}_{2}$ through the blood brain barrier. If the local metabolic production of $\mathrm{CO}_{2}$ plays any role in the responsiveness of cerebral vessels to $\mathrm{CO}_{2}$ then the greater metabolic depression that may have been produced by isoflurane anesthesia would result in less local $\mathrm{CO}_{2}$ production and conversely, halothane anesthesia would result in relatively more local $\mathrm{CO}_{2}$ which would then locally augment (isoflurane) or diminish (halothane) respectively the changes produced by altered ventilation. Perhaps a more plausible but unsubstantiated explanation is that halothane and isoflurane somehow differentially alter the kinetics of the intracellular or endothelial effects of $\mathrm{CO}_{2}$ on vasoactive substances such as calcium, nitric oxide etc. ${ }^{4}$

We also examined the more conventional Vmca $\mathrm{CO}_{2}$ responses. All patients in the isoflurane group and all but two patients in the halothane group showed a reduction in Vmca in response to a reduction in $\mathrm{P}_{\mathrm{ET}} \mathrm{CO}_{2}$. We do not know why these two particular patients demonstrated a lack of cerebrovascular $\mathrm{CO}_{2}$ responsiveness. Although we studied normal patients, our findings lend support to the observations of Adams et al. ${ }^{2}$ who found that in some neurosurgi- 
cal patients $10 \mathrm{~min}$ of hyperventilation to $\mathrm{PaCO}_{2}$ levels of less than $30 \mathrm{mmHg}$ was not enough to minimize the cerebrovascular response to halothane. ${ }^{2}$ It is possible that these neurosurgical patients were "nonresponders" akin to our two halothane patients.

Overall, there were no differences in the magnitude of cerebrovascular $\mathrm{CO}_{2}$ reactivity between isoflurane and halothane whether the two non-responders in the halothane group were included or not. This is consistent with the majority of previously published studies which have been reviewed. ${ }^{5}$ However, other studies have found a difference between these two anesthetics, with the $\mathrm{CO}_{2}$ response being greater for isoflurane. ${ }^{4-7}$ Possible explanations for these contradictory reports include the use of historical controls, small sample sizes, species differences and differing techniques used for measuring CBF and for data analyses.

There are a number of methodological issues which warrant discussion. The validity of measuring the middle cerebral arterial blood flow velocity by transcranial Doppler as an index of cerebral blood flow (CBF) has been well discussed by others. ${ }^{8}$ As cerebral vessel diameter cannot be directly measured, the absolute value of CBFV cannot be equated with the absolute value of CBF. However, previous studies have shown that changes in CBFV are proportional to changes in CBF. ${ }^{8-10}$ So as to ensure an accurate and consistent measurement of Vmca values throughout the study, we used the Medasonics probe with a tightening screw device and a head strap to limit the movement of the transducer. The range of Vmca values we report is quite consistent with that reported by others. ${ }^{11-13}$

We used $\mathrm{P}_{\mathrm{ET}} \mathrm{CO}_{2}$ measurements as a reasonable approximation of arterial $\mathrm{CO}_{2}$ measurements as we believed that intra arterial catheterization was unjustified in these healthy patients. A good correlation between $\mathrm{P}_{\mathrm{ET}} \mathrm{CO}_{2}$ and $\mathrm{PaCO}_{2}$ in anesthetized, ventilated healthy patients has been found. ${ }^{14,15}$ Although the absolute values are not necessarily identical, the relative changes track each other in a clinically useful fashion. However, Russell et al. did find that in 3 of 87 data points, $\mathrm{PaCO}_{2}$ was unchanged or increased while $\mathrm{P}_{\mathrm{ET}} \mathrm{CO}_{2}$ decreased. ${ }^{15} \mathrm{It}$ is therefore possible that such a phenomenon could account for the lack of response in the two halothane subjects. The time constant for the equilibration of alveolar and arterial $\mathrm{CO}_{2}$ in healthy individuals approximates one minute. While this may introduce a phase lag between the changes in carbon dioxide tension as seen by the cerebral vasculature and that measured at the proximal end of the endotracheal tube especially at the beginning of hyperventilation, we do not believe that such a phase lag invalidates our findings.
We used a modified Mapleson D (coaxial) breathing circuit, reducing $\mathrm{P}_{\mathrm{ET}} \mathrm{CO}_{2}$ by increasing fresh gas flow rates. ${ }^{16} \mathrm{We}$ found this method to be simple and most effective in reducing $\mathrm{P}_{\mathrm{ET}} \mathrm{CO}_{2}$ quickly with minimal changes in intrathoracic pressure, although this technique may cause a small increase in tidal volume. However this should not influence our findings as this same technique was used in all patients.

The two groups of patients were not at identical MAC values, 1.29 MAC for halothane and 1.04 MAC for isoflurane. This occurred because the study was conducted on patients undergoing surgery and ethical considerations required anesthetic depth to be titrated to clinical needs. It is conceivable that this small difference could have accounted for our findings. However, a post hoc analysis of the relationship between halothane concentration and $\mathrm{CO}_{2}$ response revealed no relationship suggesting that small differences in anesthetic depth is an unlikely explanation.

In conclusion, in our study population, the rate of change of normalized Vmca was faster in the isoflurane than in the halothane group especially in the initial few minutes. This means that the rate at which the cerebral circulation responds to changes in $\mathrm{CO}_{2}$ is faster during isoflurane than with halothane anesthesia. Indeed, for two patients in the halothane group Vmca did not change despite a change in $\mathrm{P}_{\mathrm{ET}} \mathrm{CO}_{2}$. This may be of clinical importance when cerebrovascular tone needs to be changed rapidly.

Acknowledgments

We wish to thank Peter Lok RRT for his technical assistance and Medasonics Incorporated, Fremont CA for providing the transcranial Doppler.

\section{References}

1 Adams RW, Cucchiara RF, Gronert GA, Messick JM, Michenfelder JD. Isoflurane and cerebrospinal fluid pressure in neurosurgical patients. Anesthesiology 1981; 54: 97-9.

2 Adams RW, Gronert GA, Sundt TM Jr, Michenfelder $J D$. Halothane, hypocapnia, and cerebrospinal fluid pressure in neurosurgery. Anesthesiology 1972; 37: 510-7.

3 Zar JH. Biostatistical Analysis, 2nd ed. Englewood Cliffs: Prentice-Hall Inc., 1984: 361-8.

4 Brian JE Jr. Carbon dioxide and the cerebral circulation. Anesthesiology 1998; 88: 1365-86.

5 Young WL, Prohovnik I, Correll JW, Ostapkovich N, Ornstein E, Quest DO. A comparison of cerebral blood flow reactivity to $\mathrm{CO}_{2}$ during halothane versus isoflurane anesthesia for carotid endarterectomy. Anesth Analg 1991; 73: 416-21. 
6 Drummond JC, Todd MM. The response of the feline cerebral circulation to $\mathrm{PaCO}_{2}$ during anesthesia with isoflurane and halothane and during sedation with nitrous oxide. Anesthesiology 1985; 62: 268-73.

7 Sakabe T, Nakakimura K. Effects of anesthetic agents and other drugs on cerebral blood flow, metabolism, and intracranial pressure. In: Cottrell JE, Smith DS

(Eds.). Anesthesia and Neurosurgery, 3rd ed. St. Louis: Mosby-Year Book Inc., 1994: 149-74.

8 Bishop CCR, Powell S, Rutt D, Browse NL. Transcranial Doppler measurement of middle cerebral artery blood flow velocity: a validation study. Stroke 1986; 17: 913-5.

9 Dabl A, Lindegaard K-F, Russell D, et al. A comparison of transcranial Doppler and cerebral blood flow studies to assess cerebral vasoreactivity. Stroke 1992; 23: 15-9.

10 Kochs E, Hoffman WE, Werner C, Albrecht RF, Schulte am Esch J. Cerebral blood flow velocity in relation to cerebral blood flow, cerebral metabolic rate for oxygen, and electroencephalogram analysis during isoflurane anesthesia in dogs. Anesth Analg 1993; 76: 1222-6.

11 Kuroda Y, Murakami M, Tsuruta J, Murakawa T, Sakabe T. Blood flow velocity of middle cerebral artery during prolonged anesthesia with halothane, isoflurane, and sevoflurane in humans. Anesthesiology 1997; 87: 527-32.

12 Strebel S, Kaufmann M, Baggi M, Zenklusen $U$. Cerebrovascular carbon dioxide reactivity during exposure to equipotent isoflurane and isoflurane in nitrous oxide anaesthesia. B J Anaesth 1993; 71: 272-6.

13 Young WL, Ornstein E. Cerebral and spinal cord blood flow. In: Cottrell JE, Smith DS (Eds.). Anesthesia and Neurosurgery, 3rd ed. St. Louis: Mosby-Year Book Inc., 1994: 17-57.

14 Young WL, Prohovnik I, Ornstein E, Ostapkovich N, Matteo RS. Cerebral blood flow reactivity to changes in carbon dioxide calculated using end-tidal versus arterial tensions. J Cereb Blood Flow Metab 1991; 11 : 1031-5.

15 Russell GB, Graybeal JM. The arterial to end-tidal carbon dioxide difference in neurosurgical patients during craniotomy. Anesth Analg 1995; 81: 806-10.

16 Dorsch JA, Dorsch SE. The Mapleson breathing systems. In: Understanding Anesthesia Equipment Construction, Care and Complications, 3rd ed. Baltimore: Williams \& Wilkins, 1994: 167-89. 